\title{
POPULATION DYNAMICS OF MICROARTHROPODS (ORIBATIDA AND COLLEMBOLA) IN RAINFED PADDY FIELD ECOSYSTEM IN PATI, CENTRAL JAVA
}

\author{
Rahayu Widyastati
}

\author{
Department of Soil, Faculty of Agriculture, Bogor Agricultural University \\ Jalan Meranti, Kampus IPB Darmaga Bogor 16680
}

\begin{abstract}
A study on population dynamics of microarthropods (oribatids and collembolans) in rainfed paddy field ecosystem in Pati, Central Java was undertaken with the aim to evaluate which group of soil microarthropods that dominated in each phase of rainfed paddy field. The soil fauna was collected using a soil corer of $20 \mathrm{~cm}$ diameter to a depth of $0-15 \mathrm{~cm}$, every 30 days. In the fallow, soil fauna was sampled from 4 randomized points per plot, meanwhile in the rice field phases (dry seeded rice and transplanted rice), it was sampled from 4 randomized points in the fields and in the bunds, respectively, per plot. Soil microarthropods in each season were then extracted in a Berlese funnel extractor.

During the fallow phase, the dominant soil microarthropods were Oribatida of the Acari (1200 individual $\left.\mathrm{m}^{-2}\right)$ and some groups of Collembola, numely Hypogastruridae $\left(1200\right.$ individual $\left.\mathrm{m}^{-2}\right)$, Entomobryidae (500 individual $\left.\mathrm{m}^{-2}\right)$ and Isotomidae $\left(620\right.$ individual $\left.\mathrm{m}^{-2}\right)$, meanwhile Sminthuridae of Collembola did not appear in this phase. In the rice phase, however, Sminthuridae of the Collembola occurred in high numbers, i.e., 860 individual $m^{-2}$ (field) and 610 individual $m^{-2}$ (bund).

Regarding the population dynamics of soil microarthropods in rainfed paddy field, we can assumed that oribatids and some groups of collembolans (Hypogastruridae, Entomobryidae and Isotomidae) play an important role in improving the nutrient availability during the fallow phase, meanwhile the Sminthuridae of collembolan seemed to play such role in the rice field phase, more than the other soil microarthropods.
\end{abstract}

Key words: Collembolan, oribatid, population dynamic

\section{INTRODUCTION}

Soil microarthropods are arthropods with small body size $(0.2-2.0 \mathrm{~mm})$ and live mainly in soils but not infrequently in wet biotopes. They inhabit soil crevices, pores and hollows created by larger animals because they are unable to dig their own way in soils. They are widely distributed around the world, playing an important biological role both in natural and agricultural ecosystems. As they consume plant and animal residues, graze on soil fungi and bacteria, and produce fecal pellets, these small arthropods promote the formation of soil hamus and help in improving several soil processes, such as organic matter decomposition, nutrient cycles and soil formation. They also act as vectors of numerous parasites ( $\mathrm{Vu}$ and Nguyen, 2000).

By dispersing microbial propagules, they assist in the microbial colonization of fresh litter material. After death they leave important nitrogenous waste (Minor, 2002). The most numerous microarthropods are oribatids (Acari: Oribatida) and collembolans (Insecta: Collembola). As a dominant component of soil organisms, these animals are obviously suitable bioindicators for soil health (Lee and Pankhurst 1992; Haq 1994). Vu and Nguyen (2000) reported that microarthropod community structures, particularly species diversity of oribatid and collembolan communities are related to forest decline. Therefore they can be used as bioindicators of forest plant succession.

Oribatid mites resemble small beetles and are called beetle mites. They are found in leaf litter, under bark and stones, and in the soil. Their density in forest soil can reach hundreds of thousands of individuals per square meter (Minor, 2002). They are mainly scavengers, make up a large percentage of soil fauna and are important in breaking down organic matter and promoting soil fertility (Borror et al. 1989). Oribatids comprise an important component of soil decomposers: their abundance, species composition and diversity in a particular habitat serve as good indicators of soil health (Minor, 2002). Collembolans ("springtails") live both in the surface and the depth of soil and usually occur in aggregations. They feed as scavengers on decaying vegetation and associated bacteria and fungi. They are also known to eat nematodes and dead animal matter. Many collembolans are opportunistic species capable of rapid population growth. Under favorable conditions they can reach the densities of more than 100 individuals per square inch. Collembolans are a major food source for a variety of soil predators (Minor, 2002).

The rainfed lowland paddy ecosystem that is widespread in Indonesia has great potential regarding an increase in the productive area, which has become limited in Indonesia, especially in Java (Syamsiah et al., 1994). The rainfed paddy is not irrigated and, therefore, totally depends on rainfall, which the rainwater is impounded by bunds. The rainfed paddy field system is characterized by lack of water control, with floods and drought being potential problems. Despite the increase in the area planted with rainfed lowland rice, the yields remain low. Improvement of rainfed lowland management is, therefore, needed in order to increase yields. 
This study is aiming to evaluate the dynamic of soil microarthropods with special reference to oribatids and collembolans during the fallow and rice field phases of rainfed paddy field ecosystem in Sub District Pati, Central Java, and to study which group of soil microarthropods that dominated in each phase. This information is important in predicting how actually the role of microarthropods in soil processes such as organic matter decomposition during the fallow and rice field phases of rainfed paddy field.

\section{MATERIALS AND METHOD}

\section{Study of Microarthropod Dynamics}

The density of soil microarthropods was studied in the whole study periods from the fallow to the rice field phases (dry seeded rice and transplanted rice). Dry-seeded rice (gogorancah) was grown at the beginning of the rainy season, and transplanted rice with minimum tillage (walik jerami) at the end of the rainy season. After the harvest of the second crop, the field was fallow during the dry season.

The soil fauna was collected using a soil corer of 20 $\mathrm{cm}$ diameter to a depth of $0-15 \mathrm{~cm}$ (Meyer 1996), every 30 days started from fallow (August 2000), followed by the rice field phase, and back to the early fallow (June 2001). In the fallow, soil fauna was sampled from 4 randomized points per plot, meanwhile in the rice field system, it was sampled from 4 randomized points in the fields and in the bunds, respectively, per plot. Soil microarthropods (Acari and Collembola) in each season were extracted in a Berlese funnel extractor, a device for collecting and extracting the active stages of small invertebrate animals from soil or litter (Beck et al. 1998) (Figure 1) and the collected animals were then stored in ethanol $(\mathbf{7 0} \%)$ and determined under a stereomicroscope. Acari and Collembola were classified into families and identified based on Borror et al. (1989).

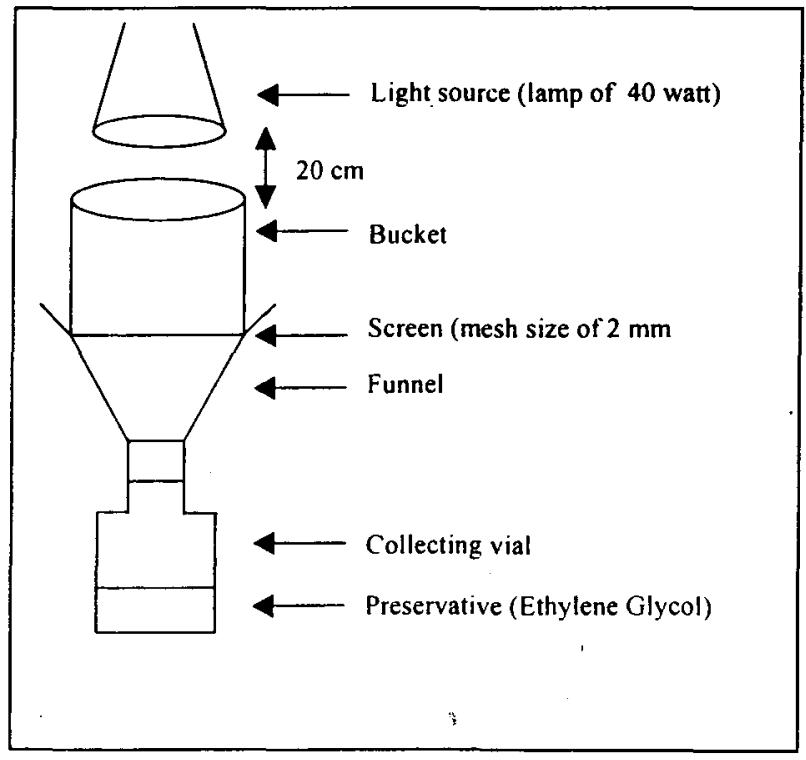

Figure 1: Berlese Funnel Extractor

\section{Calculation of Animal Abundances}

The number of individuals (abundance or density) of the extracted animals (Acari and Collembola) was calculated according to Meyer (1996):

$$
\frac{\text { IS }}{A}=1 . \mathrm{cm}^{-2}
$$

where:

IS = mean number of individuals per sample

$A$ = surface area of the corer in $\mathrm{cm}^{2}$ (Area of the corer $=\mathrm{r}^{2} \cdot \pi=(10 \mathrm{~cm})^{2} \times 3.14=314 \mathrm{~cm}^{2}$. The value was then converted into $\mathrm{m}^{2}$.)

I number of individuals

\section{RESULTS AND DISCUSSION}

\section{Dynamics of Oribatid Mites}

In terms of individual numbers, oribatid mites were the dominant group among Acari, being present at each sampling. The high population dynamics are shown in Figure 2. At the first sampling (during fallow), the number of oribatid mites was the highest (1200 individual $\mathrm{m}^{-2}$ ). According to Lavelle and Spain (2001), resistance of Acari to water and temperature stress is high, i.e., they can withstand desiccation up to $-6.0 \mathrm{Mpa}(\mathrm{pF} 5)$ before having to move to wetter areas. As a consequence, their population densities may be highest during the dry and hot seasons.

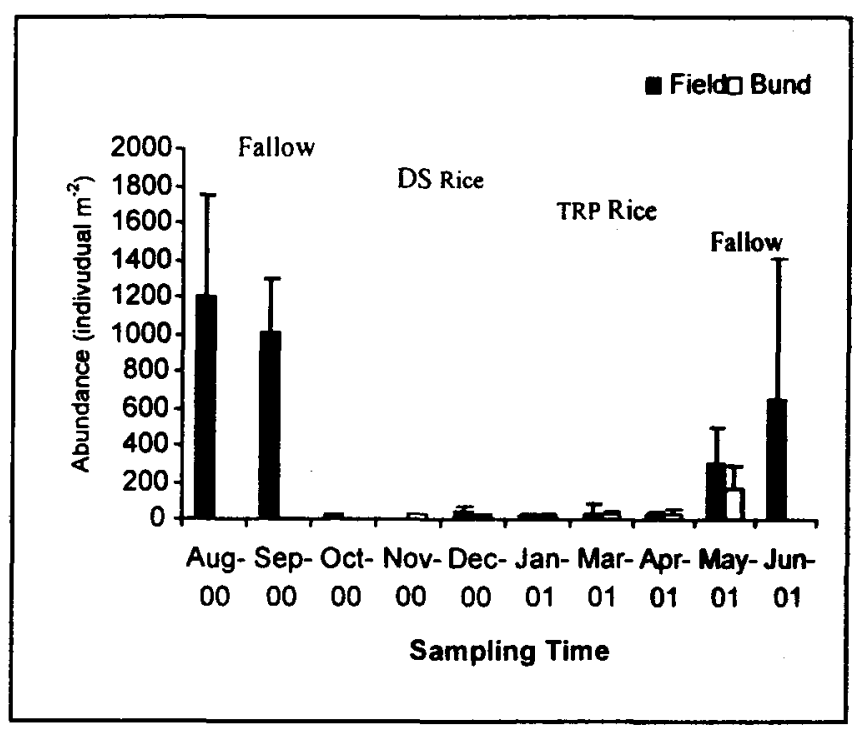

Figure 2. Dynamics of Oibatid Mtes in Fllow, Dy-Seeded Rice (DS Rice) and Transplanted Rice (TRP Rice) (soil depth $0-15 \mathrm{~cm}$ ).

Their numbers decreased at the subsequent sampling dates, i.e., approximately 1000 individual $\mathrm{m}^{-2}$ in September 2000 and 32 individual $\mathrm{m}^{-2}$ in October 2000. During the flooded periods, oribatid mites still survived, though they occurred only in very low numbers, ranging from 15 to 37 
individuals $\mathrm{m}^{-2}$. At the end of the transplanted rice season (May 2001), the number of oribatid mites started to increase and reached 303 individuals $\mathrm{m}^{-2}$ (field) and 170 individuals $\mathrm{m}^{-2}$ (bund). Oribatid mite numbers peaked again at 649 individuals $\mathrm{m}^{-2}$ in June 2001 when the field had been drained, shortly after the harvest. This condition was probably more favorable for oribatid mites.

\section{Dynamics of Collembola}

Soil fauna groups of Collembola were present in the soil at each sampling time, from the dry to the flooded phase. However, different groups appeared at each sampling time as exhibited in Figure $3,4,5$ and 6 , alternating between Sminthuridae, Hypogastruridae, Entomobryidae, and Isotomidae. During the flooded periods, Sminthuridae were the most numerous groups, but they did not appear during the fallow periods. At the beginning of the dry-seeded rice season, Sminthuridae occurred in high numbers, i.e., 860 individuals $\mathrm{m}^{-2}$ (field) and 610 individuals $\mathrm{m}^{-2}$ (bund). They were still present in December 2000 and January 2001, but in lower numbers; they occurred again in high numbers at the beginning of the transplanted rice season. Daly et al. (1998) and Alford (1999) reported that the Sminthuridae or common springtails occur mainly on wet and acid soils and on water surfaces. At the following sampling, their numbers started to decrease and reached the lowest value at the last sampling in June 2001 (Figure 3). Sminthuridae were not influenced by the sampling location (field and bund), i.e., they occurred in almost equal numbers, both in the field and in the bund.

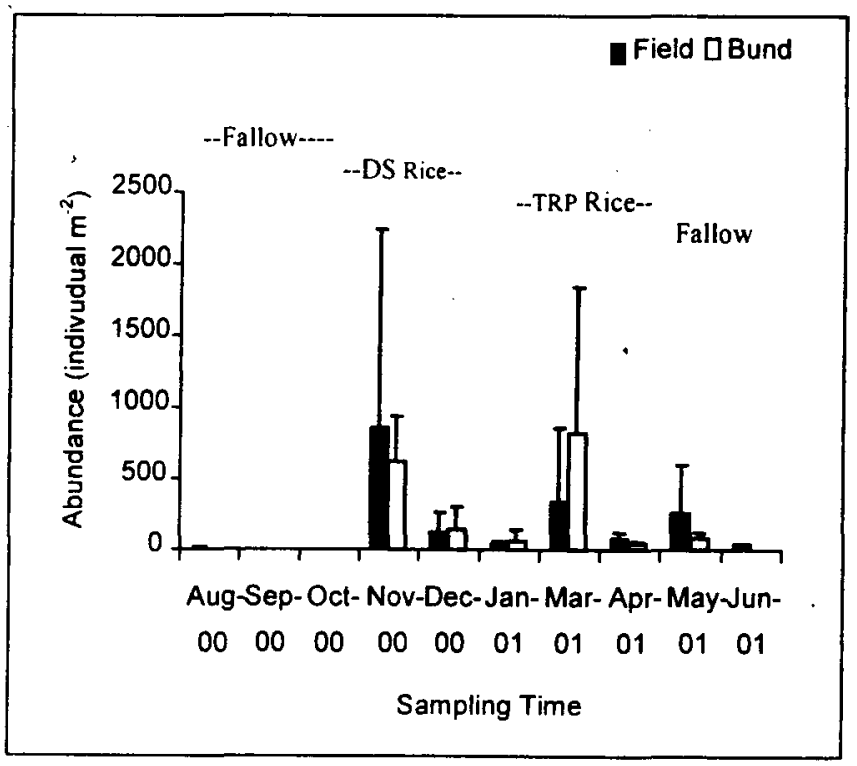

Figure 3. Dynamics of Sminthuridae in Fallow, Dry-Seeded Rice (DS Rice) and Transplanted Rice (TRP Rice) (soil depth $0-15 \mathrm{~cm}$ )

Hypogastruridae were the more dominant group among Collembola during the fallow period and they disappeared or occurred only in very low numbers during the flooded periods (Figure 4). The abundance of
Entomobryidae was very low in fallow periods; they even disappeared in September 2000 and remained low in dryseeded rice. The number of Entomobryidae started to increase in transplanted rice, particularly in the bunds, where their numbers were higher than in the fields. They reached their highest number at the subsequent sampling time, i.e., in the early fallow period (Figure 5). Isotomidae were also found abundantly during the fallow (Figure 6). The highest numbers were observed in August 2000. Numbers started to decrease in September and October 2000 , staying low during the rice field periods, especially in transplanted rice, but re-appearing in high numbers in the early fallow.

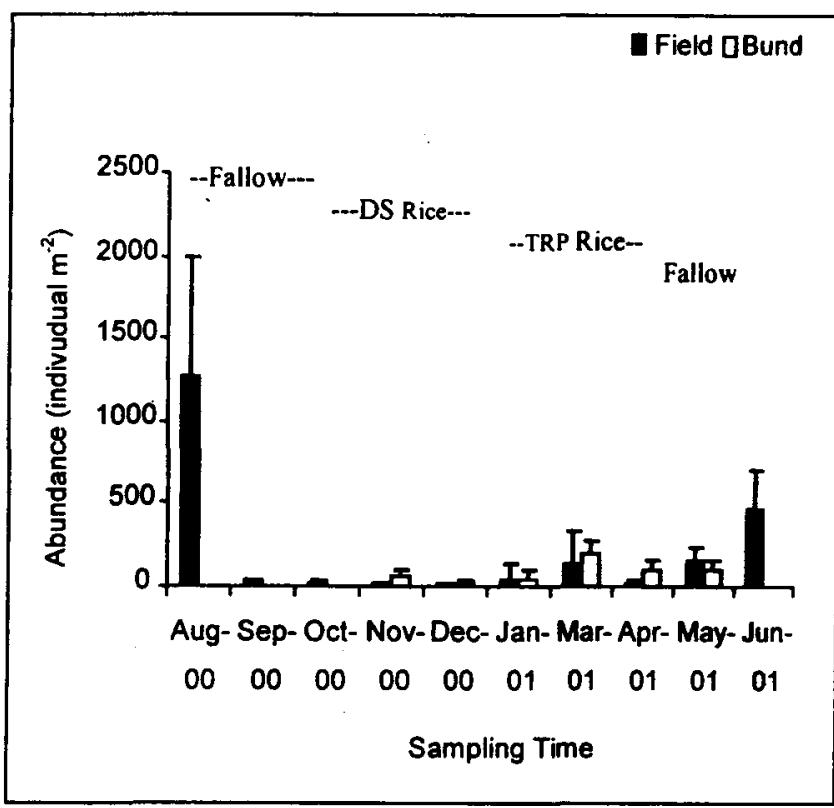

Figure 4. Dynamics of Hypogastruridae in fallow, dry-seeded rice (DS Rice) and transplanted rice (TRP Rice) (soil depth $0-15 \mathrm{~cm}$ ).

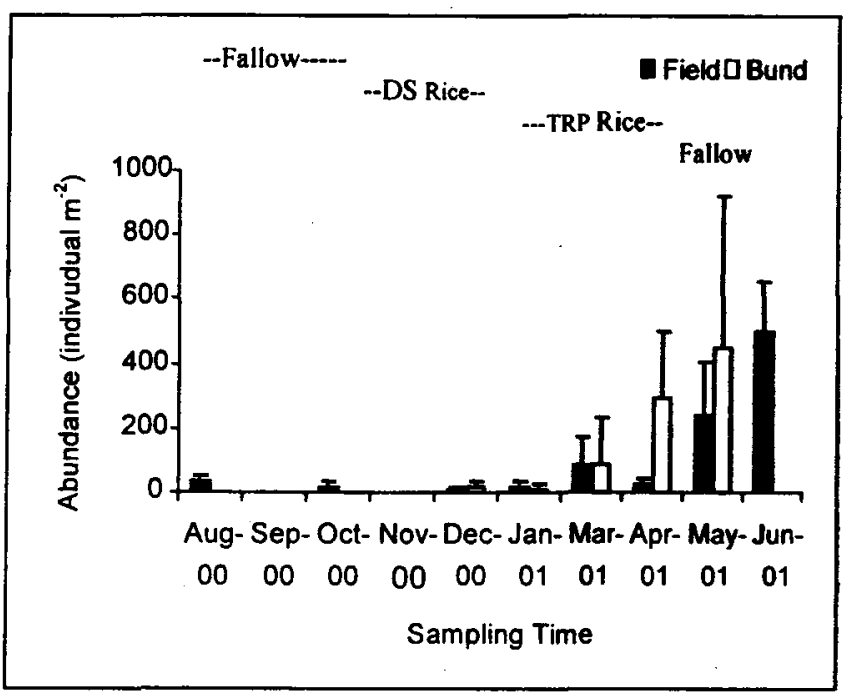

Figure 5. Dynamics of Entomobryidae in Fallow, Dry-Seeded Rice (DS Rice) and Transplanted Rice (TRP Rice) (soil depth $0-15 \mathrm{~cm}$ ). 


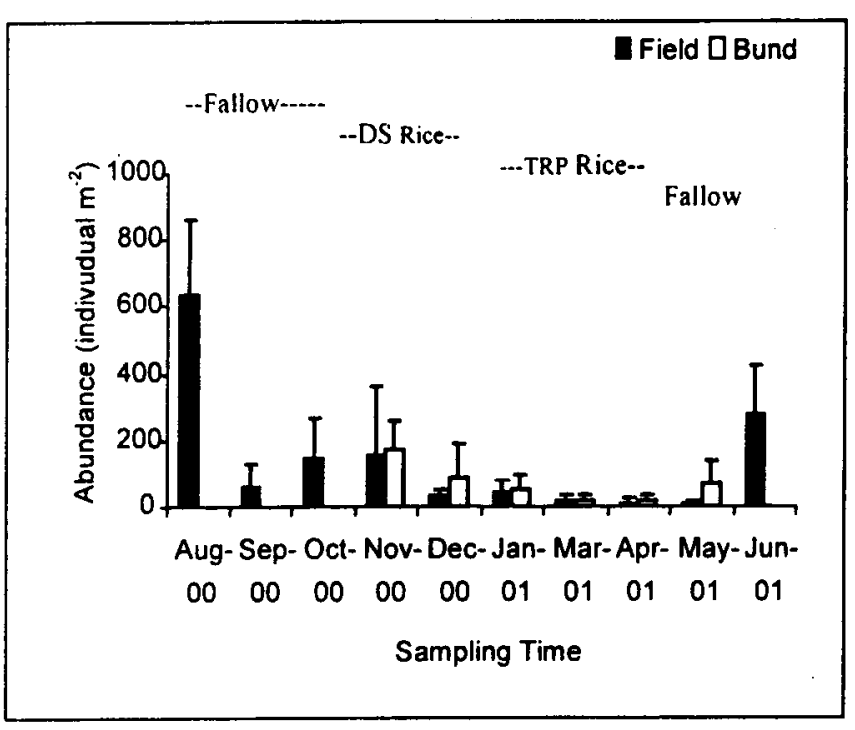

Figure 6. Dynamics of Isotomidae in Fallow, Dry-Seeded Rice (DS Rice) and Transplanted Rice (TRP Rice) (soil depth $0-15 \mathrm{~cm}$ ).

Hypogastruridae, Entomobryidae and Isotomidae of collembolan together with oribatids that occurred abundantly in the dry condition (Figures 4, 5 and 6) played an important role during the dry periods. As reported by $\mathrm{Vu}$ and Nguyen (2000) that microarthropods like oribatid mites and collembolan consume plant and animal residues, graze on soil fungi and bacteria, and produce fecal pellets, these small arthropods promote the formation of soil humus and help in improving several soil processes, such as organic matter decomposition, nutrient cycles and soil formation. So, it was assumed that these soil animals can help in improving the nutrient availability during the dry phase that will be used by rice plant in the subsequent planting season. Meanwhile the Sminthuridae of collembolan seemed to play such role in the rice field phases, more than the other soil microarthropods.

\section{CONCLUSION}

The dynamics of microarthropods in rainfed paddy field appeared to fluctuate following the seasonal changes. There was an inverse relation between population of oribatids and collembolan communities. During the dry phase or fallow period, the population of oribatids was found in high number, even in the peak fallow, they were still numerous. Their numbers, however, decreased during the rice fields or wet phase. In contrast, Sminthuridae of collembolan occurred in high numbers in wet phase and did not occur during the fallow period. Based on this result, we can assumed that oribatids and some groups of collembolans (Hypogastruridae, Entomobryidae and Isotomidae) play an important role in improving the nutrient availability during the dry phase, meanwhile the Sminthuridae of collembolan seemed to play such role in the rice field phases, more than the other soil microarthropods.

\section{REFERENCES}

Alford, D.V. 1999. A Textbook of Agricultural Entomology. Blackwell Sciences, UK.

Beck, L., H. Höfer, C. Martius, M.B. Garcia, E. Franklin and J. Römbke. 1998. Soil Fauna and litter decomposition in primary and secondary forests and a polyculture system in Amazonia- study design and methodology. Proceeding of the Third SHIFT-Workshop Manaus, BMBF, Bonn.

Borror, D.J., C.A. Triplehorn and N.F. Johnson. 1989. An Introduction to the Study of Insects. Sixth Edition. Saunders College Publishing, New York.

Daly, H.V., J.T. Doyen and A.H. Purcell. 1998. Introduction to Insect Biology and Diversity. Oxford University Press, Inc., New York.

Haq, M.A. 1994. Role of Oribatid Mites in Soil Ecosystem. In Bhandari, S.C. and L.L Somani (eds) Ecology and Biology of Soil Organisms. Agrotech Publ. Acad, Udaipur. p.143177.

Lavelle. P. and A.V. Spain. 2001. Soil Ecology. Kluwer Acad. Publ., Dordrecht.

Lee, K.E. and C.E. Pankhurst. 1992. Soil organisms and sustainable productivity. Aust. J. Soil Res., 30:855-892.

Meyer, E. 1996. Endogeic Macrofauna In Schinner F. R. Öhlinger, E. Kandeler and R. Margesin (eds) Methods in Soil Biology. Springer-Verlag, Berlin.

Minor, M. 2002. Soil Mites and Other Animals. State University of New York, College of Environ. Science and Forestry. http://web.syr.edu/ maminor/mites.html. (accessed on September, 20, 2002).

Syamsiah, I., Suprapto, A.M. Fagi and S.l. Bhuiyan. 1994. Collecting and Conserving rainwater to alleviate drought in rainfed rice lands of Indonesia. In Bhuiyan, S.I. (ed) Onfarm Reservoir Systems for Rainfed Ricelands. International Rice Research Institute, Los Banos, Philippines.

$\mathrm{Vu}$, Q.M. and T.T. Nguyen. 2000. Microarthropod community structures (Oribatei and Collembola) in Tam Dao National Park, Vietnam. J. Biosci., 25 (4):379-386. 